IN S T I T U T O

DE

M E D I C I N A

T R O P I C A L

DE

SÃO PAULO

JOURNAL OF THE SÃO PAULO INSTITUTE OF TROPICAL MEDICINE

${ }^{1}$ Pontificia Universidad Javeriana, Hospital Universitario San Ignacio, Departamento de Neurociencias, Bogotá, Colombia

${ }^{2}$ Pontificia Universidad Javeriana, Hospital Universitario San Ignacio, Departamento de Urgencias, Bogotá, Colombia

${ }^{3}$ Pontificia Universidad Javeriana, Departamento de Epidemiología Clínica y Bioestadística, Bogotá, Colombia

Correspondence to: Silvia Soler-Rangel Pontificia Universidad Javeriana, Hospital Universitario San Ignacio, Departamento de Neurociencias, Cra. 7 \#N 40 - 62, 110231 , Bogotá, Colombia

E-mail: ssoler@javeriana.edu.co

Received: 25 June 2019

Accepted: 12 November 2019
http://doi.org/10.1590/S1678-9946202062001

\section{Rabies encephalitis and extra-neural manifestations in a patient bitten by a domestic cat}

\author{
Silvia Soler-Rangel ${ }^{(1)}$, Natalie Jiménez-Restrepo ${ }^{\circledR 2}$, Daniel Nariño ${ }^{(1,}$, \\ Diego Rosselli ${ }^{\circledR 3}$
}

\section{ABSTRACT}

Rabies encephalitis is a fatal zoonotic viral disease transmitted to humans either by domestic animals like dogs and cats or by wild animals like bats, skunks and raccoons. We present the case of a 25-year-old woman admitted due to behavioral disorders, generalized paresthesiasand acute respiratory deterioration compatible with a respiratory distress syndrome (ARDS) requiring orotracheal intubation, mechanical ventilation and empirical initiation of antibiotic and antiviral therapy. Chest tomography showed pneumomediastinum and changes suggestive of pulmonary infection. In the presence of neurological symptoms, a central nervous system (CNS) infection was suspected and the cerebrospinal fluid showed no pleocytosis, hiperproteinorrachy without glucose consumption; cranial CT scan was normal. During hospitalization, the family reported that the patient was bitten by a cat 30-day prior to the onset of rabies-like symptoms, and the animal was sacrificed. The patient had an unfavorable clinical evolution, with electroencephalographic activity dissociation evidenced by video telemetry. The zoonotic exposure led to the suspected diagnosis of rabies infection. The patient died and the suspected diagnosis was confirmed by histopathology, with presence of Negri bodies on cerebellum Purkinje cells and a positive immunofluorescence test for rabies virus. Both, initial extra-neural manifestations and late reporting of rabies exposure led to delayed diagnosis.

KEYWORDS: Rabies. Encephalitis. Zoonoses. Severe acute respiratory syndrome. Extraneural manifestations.

\section{INTRODUCTION}

Rabies is a zoonotic disease, with worldwide distribution, except for Antarctica; annual human cases are estimated to be around 75,000, with highest incidence rates reported in Asia and Africa ${ }^{1,2}$. In Colombia, rabies is in the list of notifiable diseases since 1970, and there is a specific strategic plan for the elimination of human rabies transmitted by dogs or bats, which has resulted in a significant reduction of human cases $^{3,4}$.

Rabies virus is a Lyssavirus of the Rhabdoviridae family, with 16 different genotypes $^{5}$. In Colombia, the identified genotypes are V1, V3, V4, V5 and V8; genotype V1 is found in canines and eventually in bovines and equines, genotype V8 in skunks and V3 in bats, canines and cats ${ }^{3}$. Human contagion usually occurs through contact with infected saliva from dogs and cats, but numerous other animals have been implicated, including cattle and non-human primates.

Rabies is usually transmitted by the infected saliva of a canine, feline or wild animal (haematophagus bat, primate, fox or bovine) to humans, and dogs are the main urban transmitters. However, there are other ways of transmission as the 
contact between continuity solutions and infected corporal liquids, mucous contact with the virus, and in extreme circumstances, contact with aerosols containing high quantities of viruses in institutional laboratories ${ }^{6}$.

The main transmission pathway involves the contact between infected saliva and neuromuscular junctions. The incubation period varies between 1 and 3 months, but may range from 5 days to 6 or 12 months. This long latency period is explained by the low replication rate of the virus. Propagation depends on the amount of the inoculum and the tissue tropism. In bites that involve muscles, the virus is propagated in a centripetal way along motor axons, by transport vesicles, at a speed of 12 to $100 \mathrm{~mm} /$ day $^{6-8}$. After the spinal cord motor neuron infection, the virus is transmitted to interneurons, proprioceptive neurons and dorsal root ganglia ${ }^{6,8}$.

After this stage, a distance-dependent centrifuge propagation of the virus occurs, along with sensory and visceral nervous pathways. Anterograde axonal transport of the virus is inefficient, and takes weeks to arrive to extra neural organs, but explains multi-organ failure and dysautonomic symptoms on patients with rabies ${ }^{8,9}$.

Two types of clinical manifestations of rabies are typically described: paralytic and furious rabies. Furious rabies is characterized by the presentation of vegetative symptoms, behavioral changes, hydrophobia, aerophobia and paresthesias, typically presenting on the bitten limb. Conversely, paralytic rabies presents typically ascendant weakness and peripheral sensitive symptoms that can lead to coma $^{6,9}$.

Finally, after the virus has spread and has affected the central nervous system (specifically the brain stem), the final stage is the migration towards the inside of the salivary glands, where it replicates within acinar cells and is ready to be transmitted to the next host ${ }^{6}$.

The diagnosis must be confirmed with laboratory tests. Direct fluorescent antibody (DFA) test of brain tissues is the gold standard recommended by the World Health Organization ${ }^{10}$.

We present a fatal case of rabies encephalitis with extraneural manifestations leding to delayed diagnosis.

\section{CASE REPORT}

A 25-year-old female university student came to our university hospital emergency department because she had fallen a week before and had injured her right arm. She also complained that she had been feeling dizzy and had nausea with a single emetic episode five days before. The family also referred behavioral changes, incoherent language and episodes of agitation. This was the fourth time that she had consulted emergency departments in the past five days. Arm fractures had been ruled out; her dizziness had been attributed to otitis and she had been prescribed naproxen. In another occasion, she was diagnosed with an anxiety disorder and received sertraline and trazodone, which she took for only two days but suspended them because of an episode of urinary incontinence. In the last few hours she had developed a respiratory distress and fever.

On physical examination she was anxious, but oriented and alert. Her body temperature was $38.5^{\circ} \mathrm{C}$. The most striking finding was a bilateral supraclavicular subcutaneous emphysema. Her blood count showed leukocytosis $\left(17,100 / \mathrm{mm}^{3}\right)$, with neutrophilia and monocytosis $\left(1,300 / \mathrm{mm}^{3}\right)$, urine, kidney and liver tests were normal; she had prolonged coagulation times and hyperlactatemia. The chest radiograph showed the presence of pneumomediastinum and supraclavicular subcutaneous emphysema (Figure 1). The general surgeon ordered a chest CT scan to rule out esophageal perforation; the exam showed signs of an infectious bronchiolitis of the right lower lobe and pneumonia of the medial segment of the middle lobe (Figure 2). Six hours after admission the patient presented a clinical respiratory deterioration with desaturation (60\%), behavioral changes and somnolence. Suspecting a central nervous system infection, an antibiotic coverage was empirically initiated with ceftriaxone, vancomycin, ampicillin and dexamethasone. After diagnosing an acute adult respiratory distress syndrome (ARDS), she was intubated and oseltamivir was empirically initiated to treat a probable severe respiratory viral infection. HIV test was non-reactive, the cerebrospinal fluid (CSF) had a normal appearance, 2 leukocytes and 10 red blood cells per $\mathrm{mm}^{3}$ with elevated proteins $(64 \mathrm{mg} / \mathrm{dL})$; film array tests for meningitis were negative (Kit Bio Fire, Salt Lake City, Utah, USA). Viral screening tests were negative (herpes virus family, enterovirus and cytomegalovirus). Given these results, both antibiotics and oseltamivir were interrupted. There was radiological improvement of ARDS, but her neurological condition deteriorated up to the absence of brain stem reflexes (even without sedation). A right Horner syndrome (oculosympathetic paresis) was then noticed. Brain CT scan was normal. Electroencephalography (EEG) showed dysynchronic activity (Figure 3).

On day 2 of hospitalization, a government public health official, called after notification of a probable case of severe respiratory viral infection, conducted a detailed interrogation of the patient's family members. They informed that she had been bitten on her right hand by a stray cat a month earlier. The cat had been captured and taken to a veterinarian who sacrificed the animal, without any further analysis. She had then complaint of paresthesias 


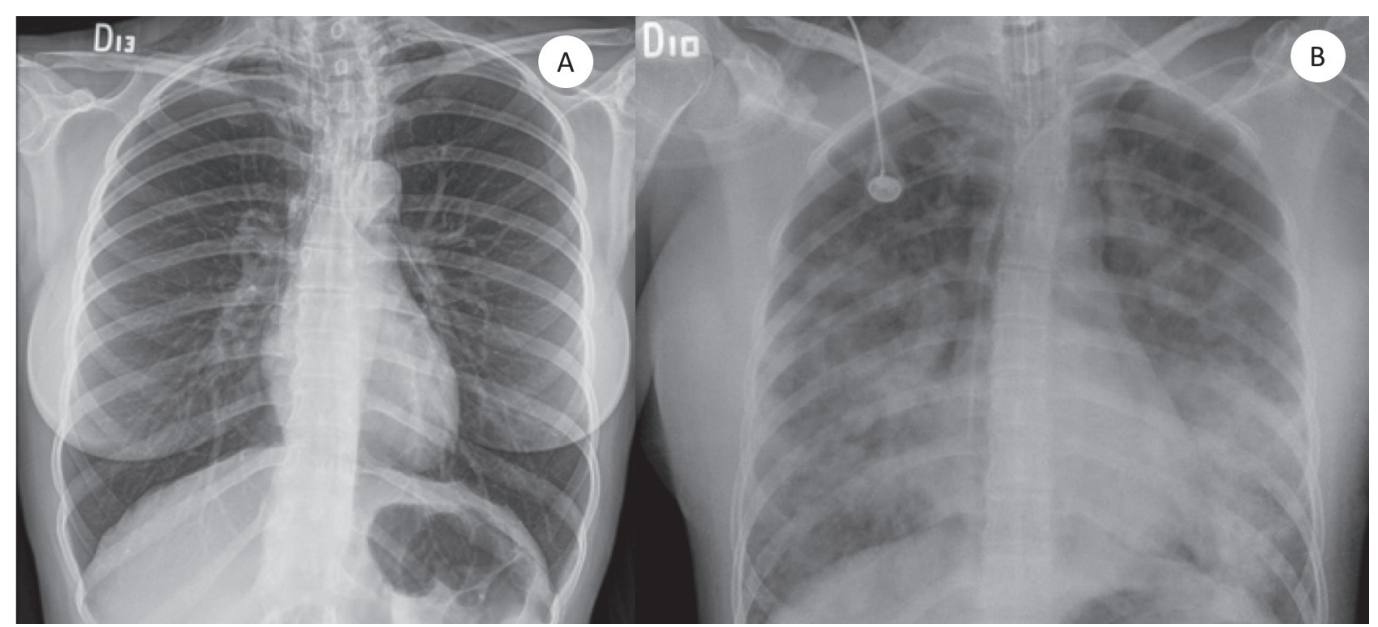

Figure 1 - A) Chest X-ray taken on admission shows the presence of subcutaneous emphysema; B) Chest X-ray taken six hours after admission showing pulmonary edema suggestive of acute respiratory distress syndrome.

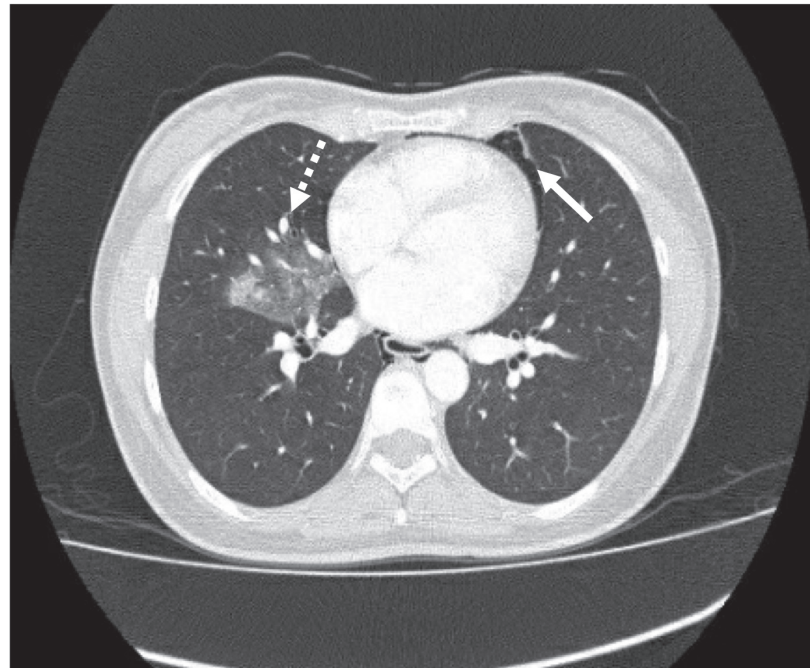

Figure 2 - Thorax CT scan showing the presence of infectious bronchiolitis in the right inferior lobe and of pneumonia in the medial segment of the medial lobe (dotted arrow) associated to pericardial emphysema (bold arrow). on her right arm that resolved spontaneously. At that moment, with a potential diagnosis of rabies encephalitis, the Milwaukee protocol was initiated. Both serum and CSF IgM antibodies were negative for rabies. On day 3 the patient presented dysautonomia, hemodynamic instability and died. Necropsy reported Negri bodies on cerebellum Purkinje cells by histopathology, a direct fluorescent antibody test was positive for rabies virus, and irreversible brain injury secondary to possible infection by rabies virus leading to severe encephalitis, respiratory failure and death.

\section{DISCUSSION}

This case of human rabies is secondary to a cat bite that occurred in a rural area (La Mesa) located $54 \mathrm{~km}$ from Colombia's capital, Bogota. It was characterized by a typical neurological presentation as rabies encephalitis and extra-neural impairment given by the ARDS-like

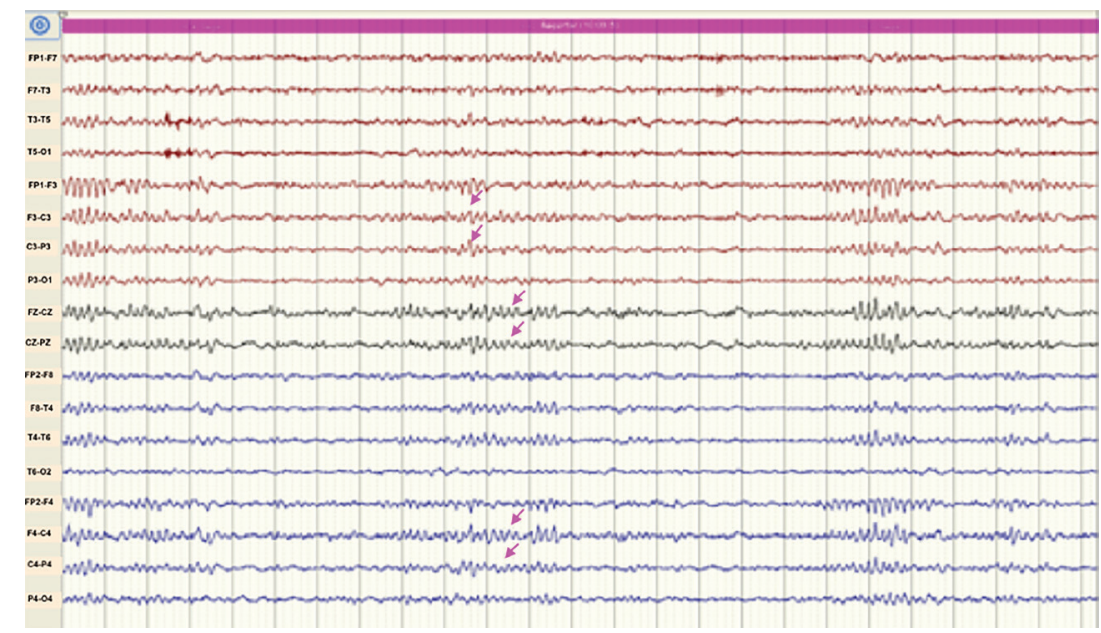

Figure 3 - Electroencephalographic (EEG) registration made while the patient was in coma, under mechanical controlled ventilation and intensive monitoring. Predominantly in frontocentral areas alpha activity (arrows) at 10 cycles is seen with a 25 millivolts amplitude mixed with a diffuse beta rhythm with low amplitude is shown (alpha). 
manifestations and subcutaneous emphysema. The latter was a confounding factor during early times after the onset of symptoms, aggravated by the delayed information of zoonotic exposure, by the family and the veterinarian.

In Colombia, rabies is in the list of notifiable diseases, both in animal and human populations and inadequate management of this information can lead to underreporting of the disease and failure to implement individual and collective actions to prevent and treat human affected beings or at high risk of rabies virus infection ${ }^{3}$.

Preventive measures include washing the wound with detergent; if the suspected animal will not be further observed, rabies vaccination should be performed. In cases with severe exposure presented by bites of animals with symptoms of rabies, both vaccination and application of rabies serum are indicated ${ }^{3}$.

The so-called "furious" type rabies encephalitis frequently presents as a clinical syndrome with unspecific symptoms such as fever, nausea, vomiting, asthenia, adynamia, weakness and pharyngeal pain, sometimes with paresthesias and itching on the affected limb. Behavioral symptoms, psychomotor agitation, seizures and fluctuations of consciousness may also be present ${ }^{7-9}$. There are some specific signs such as hydrophobia and aerophobia, that are not always present, are produced by phobic spams and present as progressive symptoms. On the EEG, dissociation between the electrophysiological activity and the clinical coma secondary to an anterior denervation of the brainstem can be seen, as described in our patient ${ }^{11,12}$. Alpha cortical activity can be found (alpha coma), suggesting a greater impairment of the diencephalon and brain stem. This pattern is explained by the physiopathology of the disease; the virus has an increased tropism for the basal and brainstem structures than for the cerebral cortex ${ }^{11,12}$.

Extra-neural involvement has been frequently documented in salivary glands and skin, nonetheless, cardiac, pulmonary, hepatic and renal impairment have been described in a smaller proportion of patients. In studies carried out in mice models, extra-neural manifestations (including ARDS) are explained by localized inflammatory responses, macrophages proliferation and increased in nitric oxide synthase levels. ARDS in patients with rabies has been explained as an extra-neural inflammation due to a longer disease duration and a higher replication of viruses, therefore, further in this field is still needed ${ }^{13}$.

In spite of the aggressive therapeutic attempts, human rabies is still a fatal disease ${ }^{4,14}$. Survival in cases with some neurological sequels have been reported, probably related to early development of neutralizing antibodies against the virus, which happens in a small proportion of patients ${ }^{15}$. The Milwaukee protocol was published in $2003^{15}$.
It includes vaccination, anti-rabies immunoglobulin administration, ribavirine, alpha-interferon and ketamine administration ${ }^{16-18}$. This therapeutic schedule was used for the first time in a 15-year old girl in Wisconsin who had been bitten a month earlier by a bat and had not been vaccinated. She received a continuous ketamine infusion (48 $\mathrm{mg} / \mathrm{kg} / \mathrm{day})$, intravenous antiretroviral therapy with ribavirin, amantadine $200 \mathrm{mg} / \mathrm{kg} /$ day and was submitted to an induced coma with midazolam and phenobarbital infusions ${ }^{18,19}$. Even though the patient survived with mild neurological sequels, the outcome of the patient has not been sufficiently explained. After the first publication of the protocol, there have been additional case reports with treatment failure ${ }^{18}$.

\section{CONCLUSION}

Rabies is a zoonotic disease with a high mortality rate. It requires an early detection and prophylaxis in order to reduce viral replication. So far, there is not an effective treatment. However, vaccination and rabies serum administration are preventive options in exposed patients who have not yet developed symptoms. Information disclosure to the general population is essential since delay in contacting the health system may have serious consequences.

Ongoing research on viral pathogenesis is required in order to find new therapies for the disease. Extra-neural manifestations, like ARDS, subcutaneous emphysema, and others can be present in patients with history of exposure to wild or domestic animals presenting rabies, and should be considered in the differential diagnosis.

\section{REFERENCES}

1. World Health Organization. Rabies. [cited 2019 May 21]. Available from: https://www.who.int/news-room/fact-sheets/ detail/rabies

2. Jackson AC. Update on rabies. Res Rep Trop Med. 2011;2:31-43.

3. Colombia. Instituto Nacional de Salud. Grupo de Vigilancia y Control de Enfermedades Transmisibles. Protocolo de vigilancia de rabia. [cited 2019 May 21]. Available from: https://www.minsalud.gov.co/Documentos\%20y\%20 Publicaciones/Protocolo\%20Rabia.pdf

4. Bustos Claro MM, Ávila Álvarez AA, Beltrán Carrascal EJ, Aguiar Martínez LG, Meek Begnini E, Prieto Beltrán AF, et al. Encefalitis rábica humana secundaria a mordedura por gato infectado por un virus rábico de origen silvestre. Infectio. 2013; 17:167-70.

5. International Committee on Taxonomy of Viruses. Rhabdoviridae: ICTV 9 ${ }^{\text {th }}$ Report, 2011. [cited 2019 May 21]. Available from: https://talk.ictvonline.org/ictv-reports/ictv_9th_report/ 
negative-sense-rna-viruses-2011/w/negrna_viruses/201/ rhabdoviridae

6. Dietzschold B, Li J, Faber M, Schnell M. Concepts in the pathogenesis of rabies. Future Virol. 2008;3:481-90.

7. Jackson AC. Rabies pathogenesis update. Rev Pan-Amaz Saude. 2010;1:167-72

8. Hemachudha T, Ugolini G, Wacharapluesadee S, Sungkarat W, Shuangshoti S, Laothamatas J. Human rabies: neuropathogenesis, diagnosis, and management. Lancet Neurol. 2013;12:498-513.

9. Hemachudha T, Laothamatas J, Rupprecht CE. Human rabies: a disease of complex neuropathogenetic mechanisms and diagnostic challenges. Lancet Neurol. 2002;1:101-9.

10. Organización Mundial de la Salud. Consulta de Expertos de la OMS sobre la rabia: segundo informe. Ginebra: OMS; 2013. [cited 2019 Nov 12]. Available from: https://www.paho. org/panaftosa/index.php?option=com_docman\&view=do wnload\&slug=consulta-expertos-oms-sobre-rabia-espanol$0 \&$ Itemid $=518$

11. Willoughby RE. Rabies: rare human infection - common questions. Infect Dis Clin North Am. 2015;29:637-50.

12. Weant KA, Baker SN. Review of human rabies prophylaxis and treatment. Crit Care Nurs Clin North Am. 2013;25:225-42.
13. Liao PH, Hsu YH, Yang HH, Wang MH, Chen LK. Involvement of extraneural tissues and upregulation of inducible nitric oxide synthase after experimental infection with rabies virus in BALB/c mice and LEW/SsN rats. Pathol Int. 2012;62:619-27.

14. Warrell MJ. The dilemma of managing human rabies encephalitis. Trop Med Int Health. 2016;21:456-7.

15. Jackson AC, Warrell MJ, Rupprecht CE, Ertl HC, Dietzschold B, O'Reilly M, et al. Management of rabies in humans. Clin Infect Dis. 2003;36:60-3.

16. Fooks AR, Banyard AC, Horton DL, Johnson N, McElhinney LM, Jackson AC. Current status of rabies and prospects for elimination. Lancet. 2014;384:1389-99.

17. Zeiler FA, Jackson AC. Critical appraisal of the Milwaukee protocol for rabies: this failed approach should be abandoned. Can J Neurol Sci. 2016;43:44-51.

18. Jackson AC. Current and future approaches to the therapy of human rabies. Antiviral Res. 2013;99:61-7.

19. Weli SC, Scott CA, Ward CA, Jackson AC. Rabies virus infection of primary neuronal cultures and adult mice: failure to demonstrate evidence of excitotoxicity. J Virol. 2006;80:10270-3. 